\title{
DESIGNING OF LOG PERIODIC ANTENNA USING FRACTAL KOCH
}

\author{
Dr. Yogesh Bhomia ${ }^{1 *}$, Dr. S.V.A.V. Prasad ${ }^{2}$, Pradeep Kumar ${ }^{3}$ \\ *1,2,3 Electronics \& Communication Department \\ *I UNIVERSAL Technical College, Jaipur, Rajasthan, India \\ ${ }^{2,3}$ Lingaya's University, Faridabad, Haryana, India
}

*Corresponding Author: -

\begin{abstract}
: -
In this paper, a log periodic fractal Koch antenna is proposed. The antenna is an amalgamation of log periodic antennas that require large lengths and fractal curves that are known for excellent form factor characteristics. The procedure is to design the LPFKA with three different numbers of iterations for better appraisal. The Zeland IE3D software has been used to analyze the performances of the designed antennas such as return loss, radiation patterns and gain. The antennas have been fabricated using FR4 laminate board thickness $1.6 \mathrm{~mm}$ and relative permittivity of 4.4 and mounted above the ground plane at a height of $6 \mathrm{~mm}$. Using fractal Koch technique, the return loss of the antenna can be reduced up to $72 \%$ when the series iteration is applied to the antennas without degrading the overall performances.
\end{abstract}

Keywords: - Antennas, Fractal, Koch, Logperiodic. 


\section{INTRODUCTION}

With the advances in communications and military systems, there is a demand for smallest possible antennas with the widest possible bandwidths. But the fundamental

limitations on size reduction of antennas drive the antenna designers to search for new techniques [1-2].

Some fractals are recursively generated selfsimilar curves that have excellent form factors. Such curves have been used to reduce the antenna size and to get multiband performance and high directivity elements [3-4]. The main advantages of fractal antenna over conventional antenna designs are its multiband operation \& reduced size. Because of fractal loading present in this type of antenna, inductance \& capacitance are added without the use of additional components. Antenna tuning units are also not required because these are 'self-loading' antennas. Fractal antenna has useful applications in cellular telephone and microwave communications [5].

\section{KOCH FRACTAL}

The expected benefit of using a fractal as a dipole antenna is to miniaturize the total height of the antenna at resonance, where resonance means having no imaginary component in the input impedance. The geometry of how this antenna could be used as a dipole is shown in Figure 1.

A Koch curve is generated by replacing the middle third of each straight section with a bent section of wire that spans the original third [6].

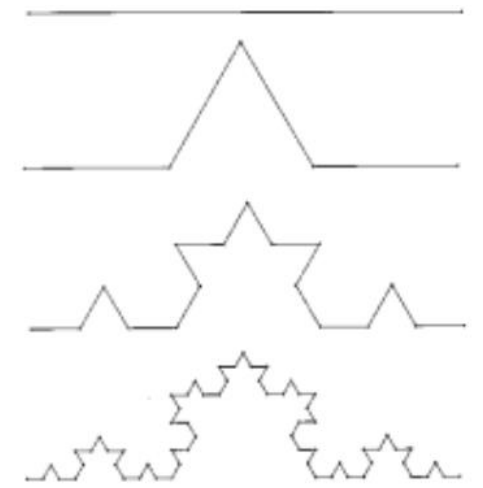

Figure 1: The first four iterations in the construction of the triangular Koch curve

Log periodic antennas have multiple elements, which resonate in a log periodic fashion. Using this property, a frequency reconfigurable log periodic antenna is proposed. Recently, work on reconfigurable log periodic antennas has been reported [7-8].

\section{LPFKA ANTENNA DESIGN}

The design of the Fractal Koch Antennas for the 1th, 2st and 3rd iterations is based on log periodic concepts. The Zeland IE3D software has been used to simulate the performance of the antennas. The antennas have been designed to operate from $1 \mathrm{GHz}$ to $5 \mathrm{GHz}$. The antenna is fabricated on $\mathrm{t}=1.6 \mathrm{~mm}$ thick FR-4 substrate with relative permittivity of $\varepsilon \mathrm{r}=4.4$ [9].

The 1th, 2st and 3rd iterations of Fractal Koch antennas are shown in Figure 3. The parameters involved length of the elements $\left(l_{n}\right)$, width of the elements $(w n)$ and distance between the elements $\left(d_{n}\right)$. Total thirteen elements are used. The number of elements influences the bandwidth of the antennas. Thus, to obtain a wider bandwidth, the number of elements needs to be increased. The length of the element $\ln$ is increase for $0.5 \mathrm{~mm}$ for previous array. The width of the element $\mathrm{wn}$ is constant with $0.2 \mathrm{~mm}$. The distance between the elements $d_{n}$ is also constant with $2.5 \mathrm{~mm}$. $l_{n}, w_{n}$ and $d_{n}$ are shown in Figure 2.

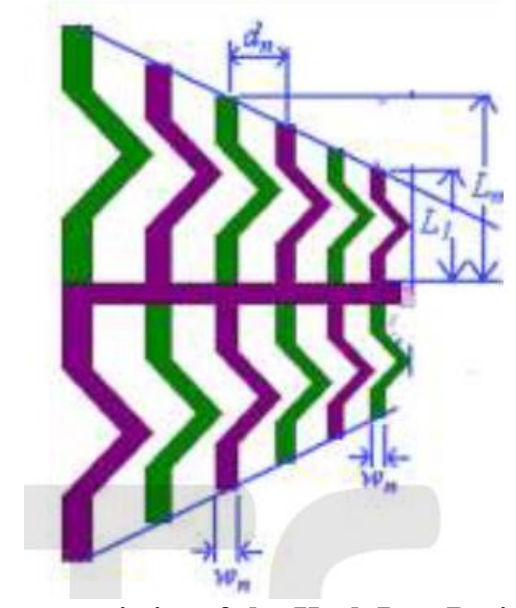

Figure 2: Design characteristics of the Koch Log-Periodic Fractal Antenna 


\section{Iteration 1:}

In the iteration 1, the main horizontalelement of the antenna is the $11 \mathrm{x} 1$ (length $\mathrm{x}$ width). All log periodic array element are attach with this main element. For feeding, use the microstirp line feed with the main element.

In iteration 1 produce the two triangular Koch in one element. The distance between two triangular Koch is $4 \mathrm{~mm}$. The height of the triangular Koch is $0.5 \mathrm{~mm}$.

\section{Iteration 2:}

In iteration 2, create a triangular Koch with height $1 \mathrm{~mm}$ in the middle of two triangular Koch of iteration 1.

\section{Iteration 3:}

In iteration 3 , recreate the middle triangular

Koch in the Koch curve. The height of the Koch curve is same as the middle triangular of the iteration 2 . The iteration 3 is called the log periodic fractal Koch antenna (LPFKA).

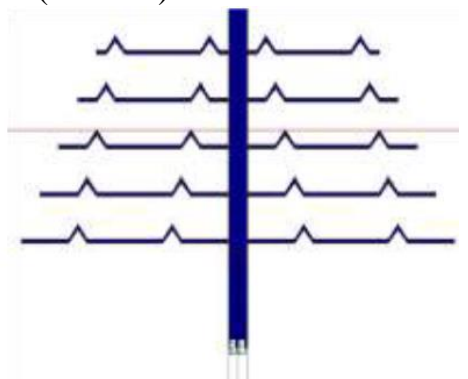

(a)Iteration1

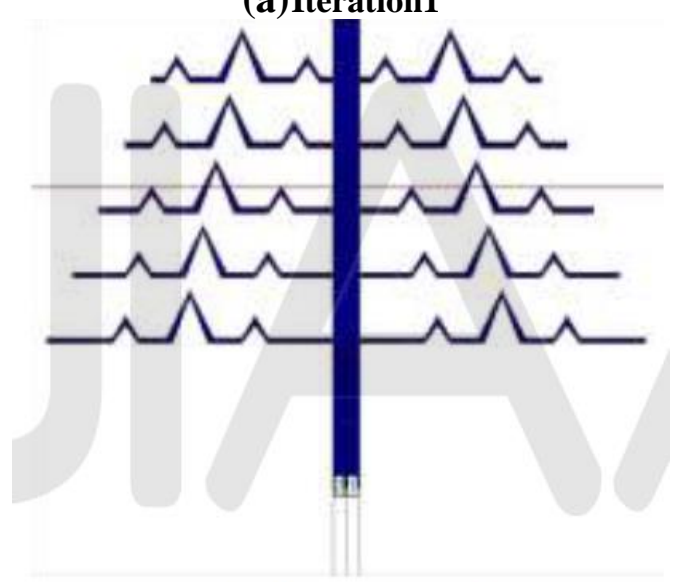

(b) Iteration 2

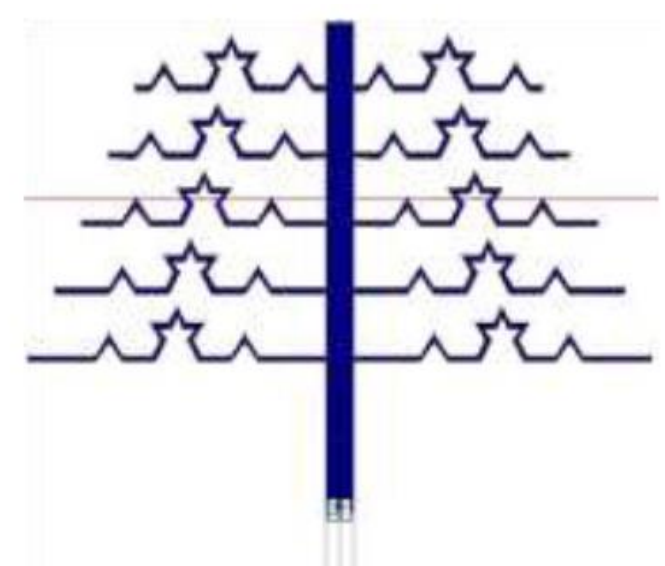

\section{(c)Iteration 3}

Figure 3: Log periodic Fractal Koch Antenna

\section{SIMULATION RESULTS}

Figures 4 show the return loss of iteration 1, iteration 2 and iteration 3, simulated with Zeland IE3D. We can see that the antenna operates at four bands which covers the frequency band around $2.6 \mathrm{GHz}$ corresponding to 4 rd generation (4G) 
for mobile communications, $5 \mathrm{GHz}$ (WiFi), $3.1 \mathrm{GHz}$, and $3.5 \mathrm{GHz}$ (WiMax).
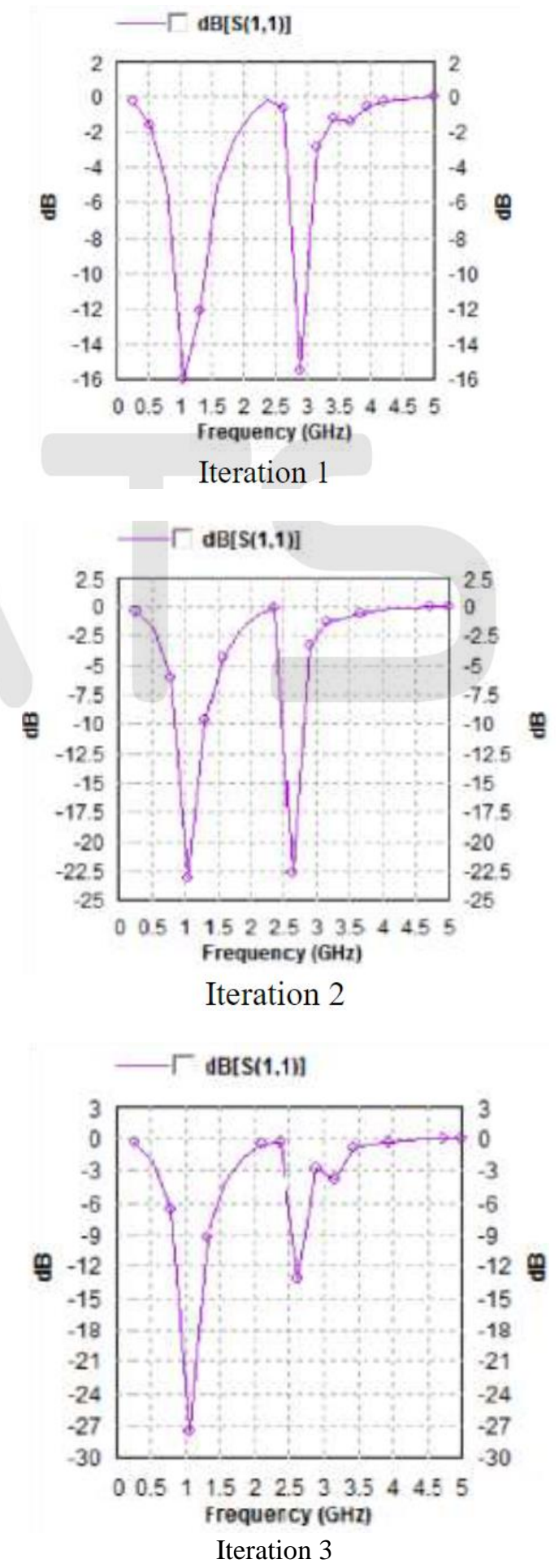

Figure 3: Return Loss of Log periodic Fractal Koch Antennas

So the proposed antenna covers multiple standards and frequencies that are very useful for current and emerging wireless and mobile communication technologies as shown in Table 1. 
Table 1: of the Fractal Koch Antennas

\begin{tabular}{|c|c|c|c|}
\hline Types & $\begin{array}{c}\text { Iteration } \\
\mathbf{1}\end{array}$ & $\begin{array}{c}\text { Iteration } \\
\mathbf{2}\end{array}$ & $\begin{array}{c}\text { Iteration } \\
\mathbf{3}\end{array}$ \\
\hline $\begin{array}{c}\text { Operating } \\
\text { Frequency } \\
\text { (GHz) }\end{array}$ & $0-5 \mathrm{GHz}$ & $0-5 \mathrm{GHz}$ & $0-5 \mathrm{GHz}$ \\
\hline $\begin{array}{c}\text { Resonant } \\
\text { Frequency }\end{array}$ & 1.053 & 1.053 & 1.053 \\
\hline VSWR & 1.38 & 1.15 & 1.08 \\
\hline Return & -15.93 & -23.09 & -27.43 \\
\hline Loss & $46 \%$ & $43 \%$ & $43 \%$ \\
\hline Bandwidth & & & \\
\hline
\end{tabular}

\section{IV.CONCLUSIONS}

The Log Periodic Fractal Koch antennas with three different structures such as the $1 \mathrm{st}, 2^{\text {nd }}$ and $3^{\text {rd }}$ iterations have been designed and simulated. The simulated and measured results in terms of return loss, radiation pattern and gain have been compared and analyzed. The numerical simulations show that the proposed antenna has the ability to work as multi-band antenna at the frequencies $5 \mathrm{GHz}, 2.6 \mathrm{GHz}, 3.5 \mathrm{GHz}$ and $3.1 \mathrm{GHz}$ with acceptable bandwidth. In addition, this antenna has VSWR $<2$ at all aforementioned resonance frequencies with high gain. The return loss of the antenna can be reduced up to $72 \%$. The compact size of the antenna geometry makes it useful for wireless applications.

\section{REFERENCES}

[1]. Younes Karfa Bekali, Mohammed Essaaidi 'Reconfigurable Microstrip Patch Antenna for Frequency Diversity Using RF MEMS' IOSR Journal of Electronics and Communication Engineering (IOSR-JECE) e-ISSN: 22782834,pISSN: 2278-8735. Volume 6, Issue 3 (May. - Jun. 2013), PP 40-43

[2]. R. L. Yadava, M. Ram and S. Das 'Multiband Triangular Fractal Antenna for Mobile Communications' International Journal of Engineering Science andTechnology Vol. 2(11), 2010, 6335-6348

[3]. S.D. Ahirwar, Y. Purushottam, T. Khumanthem, C. Sairam 'Wideband Travelling Wave Koch Dipole Antenna' Progress in Electromagnetics Research C, Vol.18, 103-110, 2011.

[4]. M.R. Hamid, P.S. Hall, P. Gardner 'Wideband Reconfigurable Log Periodic Patch Array' Progress in Electromagnetics Research C, Vol.34, 123-138,2013

[5]. Balanis, C. A., Antenna Theory: Analysis and Design, $2^{\text {nd }}$ edition, John Wiley and Sons, New York, 1997

[6]. Fawwaz Jinan Jibrael 'Multiband Cross Dipole Antenna Based On the Triangular and Quadratic Fractal Koch Curve' International Journal of Engineering (IJE) Volume (4): Issue (3)

[7]. Dimitris E. Anagnostou, Manos M. Tentzeris 'A Printed Log-Periodic KochDipole

Array

(LPKDA)' IEEE Antenna and Propagation Letters, VOL. 7, 2008

[8]. Carles Puente Baliarda, Angel Cardama 'The Koch Monopole: A Small Fractal Antenna' IEEE Transactions on Antenna and Propagation, Vol.48, No.11, November 2000

[9]. Yogesh Bhomia,Ashvini Chaturvedi,Yogesh Sharma "Microstrip Patch Antenna Combining Crown and Sierpinski Fractal-Shapes" ACMDigital Library ( ICACCI '12 Proceedings of the International Conference on Advances in Computing, Communications and Informatics),pp 1210-1213,2011. 